\title{
The School Children Mental Health in Europe (SCMHE) Project: Design and First Results
}

\author{
Viviane Kovess ${ }^{1, *}$, Mauro Giovanni Carta ${ }^{2}$, Ondine Pez ${ }^{1}$, Adina Bitfoi ${ }^{3}$, Ceren Koç ${ }^{4}$, \\ Dietmar Goelitz $^{5}$, Rowella Kuijpers ${ }^{6}$, Sigita Lesinskiene ${ }^{7}$, Zlatka Mihova ${ }^{8}$ and Roy Otten ${ }^{9}$
}

${ }^{I}$ EHESP Rennes, Sorbonne Paris Cite, EA 4057 Paris Descartes University, Paris, France; ${ }^{2}$ Centro di Psichiatria di Consulenza e Psicosomatica Azienda Ospedaliero Universitaria di Cagliari; ${ }^{3}$ The Romanian League for Mental Health, Bucharest, Romania; ${ }^{4}$ Yeniden Health and Education Society, Istanbul, Turkey; ${ }^{5}$ Institute of Psychology, University of Koblenz-Landau (Campus Koblenz), Koblenz, Germany; ${ }^{6}$ Behavioural Science Institute, Radboud University Nijmegen, Nijmegen, The Netherlands; ${ }^{7}$ Clinic of Psychiatry, Faculty of Medicine, University of Vilnius, Vilnius, Lithuania; ${ }^{8}$ New Bulgarian University, Sofia Bulgaria; ${ }^{9}$ Behavioural Science Institute, Radboud University Nijmegen, Nijmegen, The Netherlands

\begin{abstract}
Background: The School Children Mental Health in Europe (SCMHE) project aims to build up a set of indicators to collect and monitor children's mental health in an efficient and comparable methodology across the EU countries. It concerns primary schools children aged 6 to 11 years a range where few data are available whereas school interventions are promising. Methods: Three informants were used: parents, teachers and children. In selecting instruments language, instruments were selected according to the easiness to translate them: SDQ (Strengths and Difficulties Questionnaire) for parents and teachers and DI (Dominic Interactive). A two-step procedure was used: schools randomization then six children by class in each grade. Results: 9084 children from seven countries (Italy, Netherlands, Germany, Romania, Bulgaria, Lithuania, and Turkey) completed the Dominic Interactive in their own language. 6563 teachers and 6031 parents completed their questionnaire, and a total of 5574 interviews have been completed by the 3 informants. The participation rate of the children with parents in the participating schools was about $66.4 \%$. As expected teachers report more externalised problems and less internalised problems than parents. Children report more internalised problems than parents and teachers. Boys have consistently more externalised problems than girls and this is the reverse for internalised problems. Combining the diverse informants and impairment levels children with problems requiring some sort of mental health care were about 9.9\%: 76\% did not see any mental health professional: 78.7\% In Eastern countries 63.1\% in Western Europe.
\end{abstract}

Keyword: Children, dominique interactive, epidemiological survey, Europe, mental health, strengths and difficulties questionnaire.

\section{INTRODUCTION}

Promoting children and adolescents' mental health and wellbeing is supported by the literature reviews from the previous chapters. School is there presented as a major setting for interventions. In order to evaluate and monitor these interventions, data collection on child mental health most commune problems is required.

Numerous studies have examined the epidemiology of child and adolescent internalized and externalized disorders in school-age youths [1] (Roberts, Attkisson, \& Rosenblatt, 1998). Table 1 presents the results of a meta-analysis of data on the prevalence of internalized and externalized disorders in young people from more than 50 community surveys from around the world, published in the past 15 years (updated from Costello, Mustillo et al., 2004; In IOM; 2009 [2]).

In this meta analysis sample size, number of prior months that subjects were asked about in reporting their symptoms

*Address correspondence to this author at the EHESP Rennes, Sorbonne Paris Cite, EA 4057 Paris Descartes University, Paris, France; Tel: +33299022536;

E-mails: vkovess@gmail.com and viviane.kovess@ehesp.fr and age of participants were controlled. It was observed a mean estimate for any diagnosis of $17 \%$ (standard error, SE, $1.3 \%)$. Anxiety disorders were common $(8 \%)$, followed by depressive disorders (5.2\%) and ADHD (4.5\%). However, this recent comprehensive review indicated that only a small proportion of these youth actually have sufficiently severe distress or impairment to warrant intervention. Moreover, the prevalence divergences, in part due to different ways to include impairment into the diagnoses, was pointed out as a major obstacle.

Several studies have noted that boys are more likely to present behavioral and externalized disorders while girls have emotional problems (Breton et al., 1999; Fergusson et al., 1993; Goodman et al., 1998; Meltzer et al., 2003; Simonoff et al., 1997) [3-7]. Boys are more likely vulnerable to disorders with early onset, such as disruptive behavior disorders, and ADHD (Rutter, Caspi, and Moffit, 2003) [8]. Otherwise, after puberty, Depression and anxiety increase markedly in girls but not in boys (Rutter, Caspi, and Moffitt, 2003) [8].

Most of children with externalized disorders are likely to suffer from a later internalized disorders, such as anxiety or 
Table 1. Prevalence estimates of mental, emotional, and behavioral disorders in young people.

\begin{tabular}{|c|c|c|c|c|}
\hline $\begin{array}{l}\text { Diagnosis or Diagnostic Group } \\
\text { (N of studies contributing to estimate) }\end{array}$ & Prevalence \% & Standard Error (\%) & Lower 95\% & Upper $95 \%$ \\
\hline One or more disorders (44) & 17.0 & 1.3 & 14.4 & 19.6 \\
\hline Unipolar depression (31) & 5.2 & 0.7 & 4.0 & 7.0 \\
\hline Any anxiety disorder (29) & 8.0 & 1.0 & 6.2 & 10.3 \\
\hline Social phobia (15) & 4.2 & 1.1 & 2.4 & 7.3 \\
\hline Specific phobia (13) & 3.7 & 1.3 & 1.7 & 7.7 \\
\hline Panic (12) & 0.7 & 0.2 & 0.3 & 1.5 \\
\hline Conduct disorder (28) & 3.5 & 0.5 & 2.7 & 4.7 \\
\hline Oppositional defiant disorder (21) & 2.8 & 0.4 & 2.1 & 3.7 \\
\hline Substance use disorder (12) & 10.3 & 2.2 & 6.3 & 16.2 \\
\hline Alcohol use disorder (9) & 4.3 & 1.4 & 2.1 & 8.9 \\
\hline
\end{tabular}

NOTE: The prevalence estimates from each study were transformed to logit scale and their standard errors computed using the available information about the sample size and prevalences. Using weights inversely proportional to estimated variances, weighted linear regression models were fit in SAS, using PROC GENMOD with study as a fixed effect (class variable). The overall estimate (on the logit scale) and its standard error were then used to recompute the overall prevalence and its standard error using the delta method. NOTE: The table includes the 16 diagnoses or diagnostic groupings that were reported by at least 8 studies (number of studies shown in parentheses).

SOURCE: From the "preventing Mental, Emotional, and Behavioral Disorders Among Young People: Progress and Possibilities" (IOM, 2009) based on a meta-analysis for the committee by Alaattin Erkanli, Department of Biostatistics, Duke University.

depressive disorders (Loeber et al., 2000; Messer et al., 2006) $[9,10]$. Impact on children daily life is one of the recent issues on children mental health epidemiology and prevention. About half of the children with a diagnosis have a disorder that causes significant functional impairment in their relationships, cognitive, social, or emotional development (Angold, Erkanli et al., 2002; Costello, Egger and Angold, 2005) [11, 12].

Income level, family structure, number of siblings, economic activity and social class are the most current risk factors. Conduct disorders have strongest association with socioeconomic and family characteristics (Ford, Goodman and Meltzer, 2004) [13]. Poverty, adverse life events, low social, economic status and ethnicity have been largely associated with an increased prevalence of childhood psychiatric disorders (Costello et al., 1996; Goodman et al., 1998; Rutter et al., 1976) [5, 14, 15]. Disadvantaged families and urban environments have been linked with behavioral problems in both childhood and early adolescence (Costello et al., 1996; Fombonne, 1994; Rutter et al., 1976) [14-16].

Maternal smoking during pregnancy is a predictor of internalizing as well as externalizing psychopathology in offspring (Ashford et al., 2008; Batstra et al. 2003; Fergusson et al. 1993; Wakschlag et al., 2002, 2006; Wasserman et al., 2001; Weissman et al., 1999; Williams et al., 1998) [17-24]. The association between prenatal smoking and internalizing and externalizing problems persists throughout childhood and late adolescence.
Children of parents with alcohol problems are at greater risk for emotional and behavioral problems (Chen \& Weitzman, 2005; DeLucia, Belz, \& Chassin, 2001; Edwards, Leonard, \& Eiden, 2001) [25-27]. The link between the parental alcohol consumption and the presence of emotional or behavioral problems in childhood have been explained with the lack of positive parenting attitudes and to poor parental control of their child, destructive marital conflict and parenting problems (e.g., Keller et al., 2011) [28].

Indeed negative parenting attitudes may have an impact on children's mental health (Johnson et al., 2001) [29]. Permissive parenting style of mentally ill mothers was linked with higher symptoms of adolescent depression and anxiety related to children who received positive and directive parenting style (Oyserman, Bybee and Mowbray, 2002) [30]. Children with mental disorders were more likely to be frequently punished than those with no mental disorders. In the UK survey (Meltzer et al. 2003) [6], results from parents' questionnaire showed that children with mental health were more frequently shouted at $(42 \%)$, sent to their room $(18 \%)$ and grounded $(17 \%)$ than children without mental health problems.

Studies, which investigated the mental health service use since the 1980s and in the past decade, clearly noticed that most children who need care are not getting it [31], Horwitz et al., 1992 and 1998; Horwitz, Gary, Briggs-Gowan, \& Carter, 2003.) [32-34]. Only $10-15 \%$ of young people with mental health problems receive help from existing mental 
health services (WHO 2005) [35]. The reasons of low rates of mental health service use in childhood and adolescence may include unavailability of services, financial obstacles, parents' lack of awareness, motivation or mental health problem recognition, family history of mental illness, lack of appropriate referral pathways, and use of alternative kinds of help. Moreover, the low proportion of children and adolescents who asked professional help could be explained by the difficulty to parents to recognize the presence of mental health problems in the child's behaviour. The presence of additional physical health and school related problems increased the rate of help-seeking for child psychopathology (Zwaanswijk et al., 2003) [36]. This increase was not the results of better parental problems recognition but only due to the importance of teacher in the detection of the children with mental health problems.

Most of the above references are issued from US, Canada and UK because large epidemiological surveys on school children population are relatively rare in most of the EU state members and hard to compare because, for the few existing, instruments and sampling designs are very different. Indeed obstacles to conduct school surveys in a comparable way are many; among them the very large number of languages in the EU, the cost of conducting large surveys and the difficulties to obtain administrative authorisations to involve schools, to mention the few. These obstacles have to be overcome since results from the countries where surveys are available could not be applied to the diversity of the EU member states plus, as we will see in this chapter, inter member state comparisons are very informative because it allows to compare the impact of different policies in the diverse MS on children mental health and well being.

The School Children Mental Health in Europe (SCMHE) project has been financed by the EU (Grant number 2006336) in order to build up a set of indicators to collect and monitor children's mental health and its major risk factors in an efficient and comparable methodology across the EU countries. In order to evaluate the feasibility of the proposal, large school surveys were experimented in seven European countries. Primary school children population : 6 to 11 year old children were targeted because few data are available for this age range when school interventions seem easier to implement before the symptoms become long lasting and have produced their deleterious effects on school adaptation.

This chapter will report the proposal: the instruments that have been selected in order to measure the children mental health and the most pertinent risk factors, the sampling design and provides some comparative data on prevalence and access to care. In addition it will illustrate the applications by reporting the outlines of some published papers, which combine data on diverse MS policies or global indicators and children mental health as measured by the surveys.

\section{INSTRUMENTS SELECTION}

Seven instruments were pre-selected as the most used structured and semi-structured interviews in the literature for the target population: the Dominic Interactive (DI; Valla, Bergeron \& Smolla, 2000) [37], the Child and Adolescent Psychiatric Assessment (CAPA; Angold et al., 1995; Angold and Costello, 2000 Not Found, chaged with:Angold \& Costello 1995) [38, 39], the Development and Well-Being Assessment (DAWBA; Goodman, Ford, Richards, Gatward, \& Meltzer, 2000a) [40], the Strength and Difficulties Questionnaire (SDQ; Goodman, 1997) [41], the Diagnostic Interview Schedule for Children (DISC; Shaffer et al., 1996) [42], the Diagnostic Interview for Children and Adolescents (DICA; Reich, 2000;) and Child Behaviour CheckList (CBCL; Achenbach, 1981; Achenbach and Rescorla, 2001) [43, 44].

All instruments except one (DI) relies on informants usually parents or teachers for children below 11 year. Discrepancies between informants were expected and recommendations were to collect data from the three informants: children, parents and teachers whenever possible. We decided that MH data will be collected from the three informants in a self administrative manner so we have to produce a parent questionnaire and a teacher questionnaire which completed the DI which was proposed trough a computer. Parents and teachers questionnaires were in a pencil paper mode but in one country this was offered on a computerized manner trough a dedicated website.

Language availability was a major concern for this project because so many languages are spoken in the EU. When translation was not available, instruments were selected according to the easiness to translate them. According these criteria SDQ which exists ${ }^{1}$ in most of the languages required for parents and teachers and $\mathrm{DI}^{2}$ which is supported by pictures integrated into a computer program with few short sentences to be translated have been selected as a kit that could be developed for any EU country desiring to implement such survey.

The translation process was concerning SDQ and DI for the countries where this was not available such as Italy, Romania, Bulgaria, Lithuania and Turkey for both or one of them. Translation was done by experts with back translation with the collaboration of SDQ and DI authors which allows them to integrate these translations into their official web site.

Papers on DI and SDQ translation validation are either submitted or being written. Moreover an external validation process was set up on 578 children from the seven countries in child psychiatric clinics and few no cases using the DAWBA which combines informant report and clinical rating.

DI is a self-administered questionnaire for children aged to 6 to 11 years old. It's a computerized program which proposed to the children to follow a character, usually named Dominic, represented in the cartoon depicts the gender of the child assessed in different situations. Questions are asked in order to ask if the children feel the same than Dominic. 91 precise situations represent symptoms for 7 common DSMIV childhood psychopathologies (Attention Deficit/Hyperactivity Disorder (ADHD), Conduct Disorder, Oppositional Defiant, Phobias, Separation Anxiety Disorder, Generalized Anxiety Disorder and Major Depressive Disorder) placed in various daily life situations: at home, at school and with other children. The pictures, texts and voices illus-

\footnotetext{
www.sdq.org

${ }^{2}$ www.dominic interactive.com
} 
trate the abstract emotional and behavioral content of most frequent mental health problems based on DSM-IV symptomatology.

Because the Dominic Interactive is self-administered and computerized, only one research assistant is needed for 5 to 6 interviews. The DI is easy to use: Children, after a short tutorial, respond by using the mouse to click on "Yes" or "No" boxes, thus disclosing their own reactions when they are faced with these situations Cf. Fig. (1). The child's choices are recorded and analyzed automatically by the computer afterward.

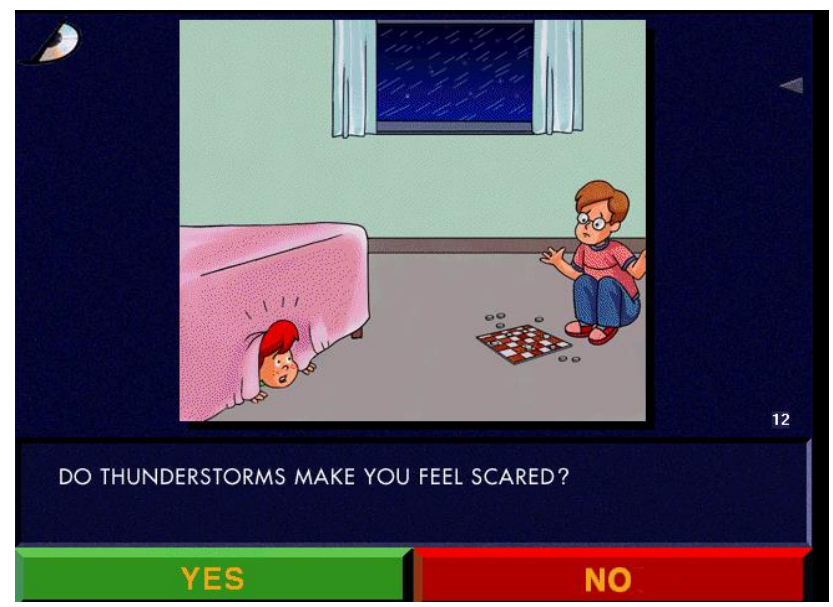

Fig. (1). Example of DI's questions: "Do thunderstorms make you feel scared?"

At the end, an algorithm assigns the child to one of the three diagnostic probability categories: "likely absent," "possible" and "likely present" using cut off points reported by Valla et al. (2000) [37]. The DI proposes probabilities to have an Internalized or Externalized diagnosis. For each 7 diagnosis a score is calculated from the different questions/cartoons situations proposed to the child. In Europe it has been validated in France (Shojae 2009) [45].

SDQ, a 25-items behavioural screening questionnaire for children 4-16 years old. (SDQ; Goodman, 1997) [41], predicts probability for psychiatric disorders in child trough an algorithm proposed by its author Robert Goodman (Goodman et al. 2000) [40]. SDQ is constituted of 5 subscales which describe positive and negative attributes of children: 1) emotional symptoms ( 5 items), 2) conduct problems (5 items), 3) hyperactivity-inattention problems (5 items), 4) peer relationship problem (5 items) and 5) one positive dimension: prosocial behaviour (5 items). "Total difficulties" subscale is the sum of the four first disorders listed above (Emotional symptoms, conduct, Hyperactivity-inattention and peer-relationship problems). "Impact" dimension was calculated from 5 questions for parent, such as Distress question "do the difficulties upset or distress your child?", impact on home, on friendships, classroom and leisure items. Supplements questions are proposed in order to measure the impact of these difficulties on children and their environment such as problem severity, distress to the child, and interference in everyday life and burden to others. This provides useful additional information for clinicians and researchers with an interest in psychiatric caseness and the determinants of service use (Goodman, 1999) [46].

SDQ has been largely used in diverse surveys in the EU noteworthy in UK (Melzer 2003) not found Goodman et al. 2003) [47], Germany (Woerner 2004) [48], the Netherlands (Van Widenfelt BM 2003) [49] Nordic countries (Smedje H 1999, Obel 2004, Malmberg 2003, Koskelainen M 2000) [50-53], France (Shojae 2009) [45] and in Southern Europe (Marzocchi 2004) [54].

Most of the socio demographic risk factors were collected by the parent questionnaire such as family composition, parent's age, education and employment statute, country of origin plus question on tobacco consumption including during pregnancy and alcohol behaviour by a 10-item Alcohol Use Disorders Identification Test (AUDIT; Saunders et al., 1993) [55], developed by the World Health Organization (WHO).

In addition the Parenting Scale (Arnold et al., 1993) [56], a 30-item self-report scale covering 3 dysfunctional discipline styles: laxness, over-reactivity and verbosity was added. Parents have to indicate their tendencies to use specific discipline strategies using 7-point Likert scales, where 7 indicates a high probability of making the discipline mistake and 1 indicates a high probability of using an effective, alternative discipline strategy. The total score is the average of all items responses. For calculating scores regarding the 3 different dysfunctionning discipline styles, the average score of the responses on the items on that factor was calculated. Two dimensions were added to the parenting attitudes: autonomy and care, from the Parent Behaviors and Attitudes Questionnaire (PBAQ; Bergeron et al., 1992) [57]. In Italy, 3 dimensions (including punitive behavior) were used since the Parenting scale was not asked. The Care score was the average of 8 items (CF. questions at E2) and 7 items for the Autonomy score (Cf. questions at E3). Parenting attitudes (PBAQ) were classified in 3 categories for each factor: Weak, normal and strong attitude. In addition, a question about the presence of difficulties in the parent and child relationship was asked.

Regarding the parents' mental health measure as a main risk factor, 3 SF-36-subscales were used (Ware and Sherbourne, 1992) [58]. This instrument evaluates negative mental health: the psychological distress and impairment attributable to $\mathrm{MH}$ and positive mental health (vitality). It has been widely studied and validated in many languages (International Quality Of Life Assessment [IQOLA]; Ware and Gandek, 1998) [59]. The SF-36 has good construct validity, high internal consistency and high test-retest reliability (Ware et al., 1993, 1994) [60, 61].

In addition some children's physical health data were asked to the parents: child's weight and height, presence of asthma/wheezing, eczema and rhinitis, domestic injuries, children life style (exercise, tv and video games time spent) and child's use of care for mental health problems toward diverse providers.

A self administered questionnaire was provided to the teachers containing SDQ and diverse school competencies levels. 


\section{SAMPLE AND PROCEDURES}

\subsection{Sampling}

Potential participants were selected from primary schools in each countries. Primary schools were randomly selected in each participating country, classes were randomly selected in each school and 5 to 6 children were randomly selected in each class. In general, 48 children were randomly selected in each school, from 10 for Primary schools with 5 grades to 12 for Primary schools with 4 grades. A total of 45 to 49 schools were needed to obtain about 2500 possible interviews. The Fig. (2) explains the different step for selecting randomly children in each school. Schools were randomly selected, and then we checked if there had more than 12 children by grade. If a school had more than 12 children by grade, only 12 children were randomly selected; on the contrary (less than 12), another school was selected in the same area and characteristics in order to complete the correct number of children by schools.

Noteworthy in Germany and in the Netherlands it was very hard to find schools accepting to participate due to many researches going on, so the number of children randomly selected at schools was higher than the other countries.

\subsection{Ethical Committee and Authorizations}

All the country partners received authorization and support from their government trough their Ministry of Education or Health. Some of the countries only need the authorization from the Ministry of Education (Romania, Bulgaria, and Turkey) for the remaining an ethical approval from the corresponding authority was required and obtained.
Each partner provides a list of schools for the selected areas and then randomly selected schools. The partners were in charge to contact schools. In some countries (Bulgaria and Romania) the Ministry of Education directly sent an information letter with all the contact information in order to participate. Implication of the concerned authority was one of essential step to get schools involved. But for most of the other countries, the teams sent information letter, with the authorization from the ministry, directly to schools and then contact them by phone. At school, the contact was usually the director or vice director. They were in charge to give the list of children, or to select the children randomly and then to give the information and the consent letter to the parents by the children bias.

Parents received the information letter with the consent letter to be sent back to the school with their response; if the parents did not send back the letter of consent with the refusal, the questionnaire was proposed to the three informants. Teachers were allowed to refuse to participate as well; however once the school accepted the survey, teachers were usually positively involved.

The process was identical in each of the countries except in Italy where children were given the DI individually; the six randomly selected children from a class (or less if some parents have sent a refusal) were called and sited in a special room where six computers were waiting for them with ear devices; adequate language, gender was selected by the research attendant who enter their age and a ID number and the child starts the DI. Then he received his parent questionnaire that has to be remit trough the school transmission book where the ID number was written as it was for the teacher questionnaire that was given by the research assistant to the class teacher for the six selected students. At the end of the

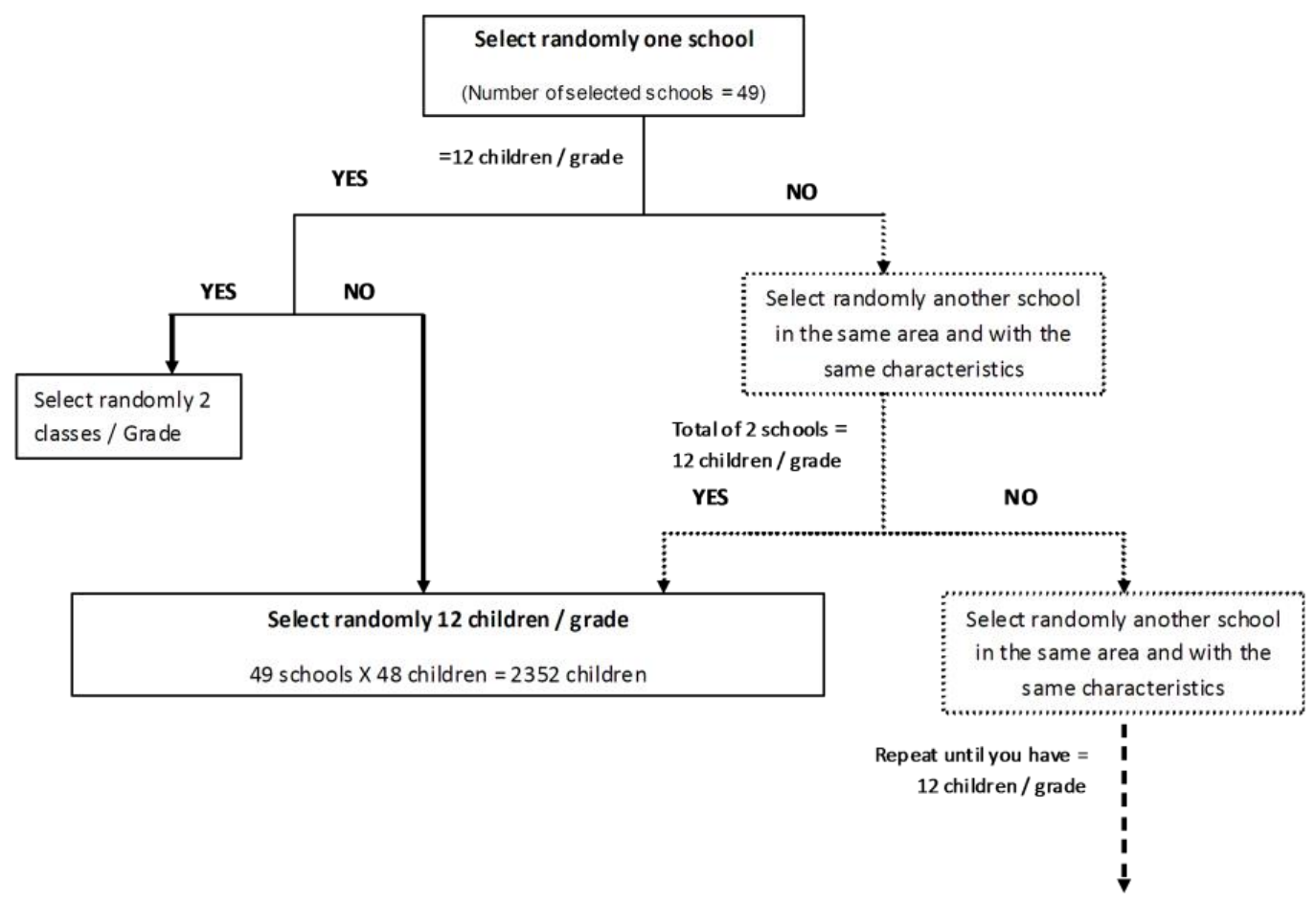

Fig. (2). Sampling procedure for a country with 4 grades school. 
day, the research assistant leaves with the computers filled with the DI, and with the teacher questionnaires. A secure box was installed at the school where the parents will give back their questionnaires once filled that will be either sent directly to the place where data were entered or collected by the research assistant.

\section{RESULTS}

9084 children from seven countries (Italy, Netherlands, Germany, Romania, Bulgaria, Lithuania, and Turkey) completed the Dominic Interactive in their own language. 6563 teachers and 6031 parents completed their questionnaire, and a total of 5574 interviews have been completed by the 3 informants. The participation rate of the children with parents in the participating schools was about $66.4 \%$. see Table 2.

\subsection{Main Children Mental Health Results}

Figs. (3, 4 and 5) present the results for externalised and internalised problems in the different countries by informants: parents, teachers and children.

Problems are more frequent in the West that in the East; Teachers report more externalised problems and less internalised problems than parents. Children report more internalised problems than parents and teachers. Boys have consistently more externalised problems than girls and this is the reverse for internalised problems.

\subsection{Access to Care for Mental Health Probles}

Responses from the three different informants regarding the child's mental health problems were combined with the SDQ impact variable in order to produce 4 degrees of mental health care: Children with mental health problems requiring psychiatric care was identified by at least two informants and presented impact. Children with problems requiring nonpsychiatric care but still some mental health needs within the primary health care system was identified by at least two informants with or without impact. Problems requiring mental health care grouped the problems requiring psychiatric care and problems not requiring psychiatric care. The two last categories were: children not requiring mental health care were identified by only one informant with or without impact and finally, children without any mental health problems.

According to the above definitions on average $4.4 \%$ : have mental health problems requiring psychiatric care. The highest percentage was found in Lithuania (5.7\%) and Germany $(5.1 \%)$ and lowest In Italy $(3.2 \%)$. Among those children $69.8 \%$ were not in contact with any mental health professional; this percentage was ranged from $50 \%$ in Italy to $91.1 \%$ in Bulgaria. However, $64.3 \%$ were in contact with general practitioner: from $18.2 \%$ in Turkey to $89.7 \%$ in Romania. $42.8 \%$ were in contact with a paediatrician: from $26.2 \%$ in Lithuania to $78.3 \%$ in Italy. Less than $20 \%$ among children with psychiatric needs were in contact with a psychologist, psychoanalyst or psychotherapist and or psychiatrist. Bulgaria had the lowest rate with $4.4 \%$ for psychiatrist and the lowest rate for psychologist was found in Germany with $5.6 \%$. Italy had the highest rate for psychiatrist $(39.1 \%)$ and Romania had the highest for psychologist with $50 \%$.

$5.1 \%$ of the children had mental health problems requiring non-psychiatric care but need mental health care within the primary health care system. Lithuania had the highest rate $(8 \%)$ and the lowest rate was found in Italy $(2.3 \%)$. Among those children $76.4 \%$ were not in contact with any mental health professional; this percentage was ranged from $59.5 \%$ in Romania and $92.7 \%$ in Bulgaria. As for children with psychiatric needs, most of the children were mainly in contact with a general practitioner $(64.6 \%)$ with a highest

Table 2. Number of survey participants for the SCMHE project by countries.

\begin{tabular}{|c|c|c|c|c|c|c|c|c|c|}
\hline Countries & Bulgaria & $\begin{array}{l}\text { Germany } \\
\text { East }\end{array}$ & $\begin{array}{c}\text { Germany } \\
\text { West }\end{array}$ & Italy & Lithuania & $\begin{array}{c}\text { The } \\
\text { Netherlands }\end{array}$ & Romania & Turkey & Total \\
\hline \multicolumn{10}{|l|}{ School participation } \\
\hline Number of potential schools & 48 & 150 & 150 & 63 & 49 & 48 & 45 & 46 & 599 \\
\hline Number of participating schools & 44 & 12 & 11 & 55 & 42 & 13 & 43 & 38 & 261 \\
\hline$\%$ school participation & $91.7 \%$ & $8.0 \%$ & $7.3 \%$ & $87.3 \%$ & $85.7 \%$ & $27.1 \%$ & $95.6 \%$ & $82.6 \%$ & $43.6 \%$ \\
\hline \multicolumn{10}{|l|}{ Children participation } \\
\hline Number of children in participating schools & 2160 & 825 & 826 & 2750 & 2208 & 1660 & 2064 & 1824 & 14317 \\
\hline Children & 1385 & 441 & 445 & 1721 & 1275 & 1503 & 1393 & 921 & 9084 \\
\hline$\%$ of children participation & $64.12 \%$ & $53.45 \%$ & $53.87 \%$ & $62.58 \%$ & $57.74 \%$ & $90.54 \%$ & $67.49 \%$ & $50.49 \%$ & $63.45 \%$ \\
\hline \multicolumn{10}{|l|}{ Informant participation } \\
\hline Parents & 1081 & 240 & 238 & 757 & 1159 & 684 & 1206 & 666 & 6031 \\
\hline Teachers & 1267 & 373 & 362 & 1323 & 1226 & 1292 & 1171 & 872 & 7886 \\
\hline 3 informants & 996 & 203 & 194 & 757 & 1118 & 558 & 1106 & 642 & 5574 \\
\hline$\%$ of participating children with parent & $78.05 \%$ & $54.42 \%$ & $53.48 \%$ & $43.99 \%$ & $90.90 \%$ & $45.51 \%$ & $86.58 \%$ & $72.31 \%$ & $66.39 \%$ \\
\hline
\end{tabular}




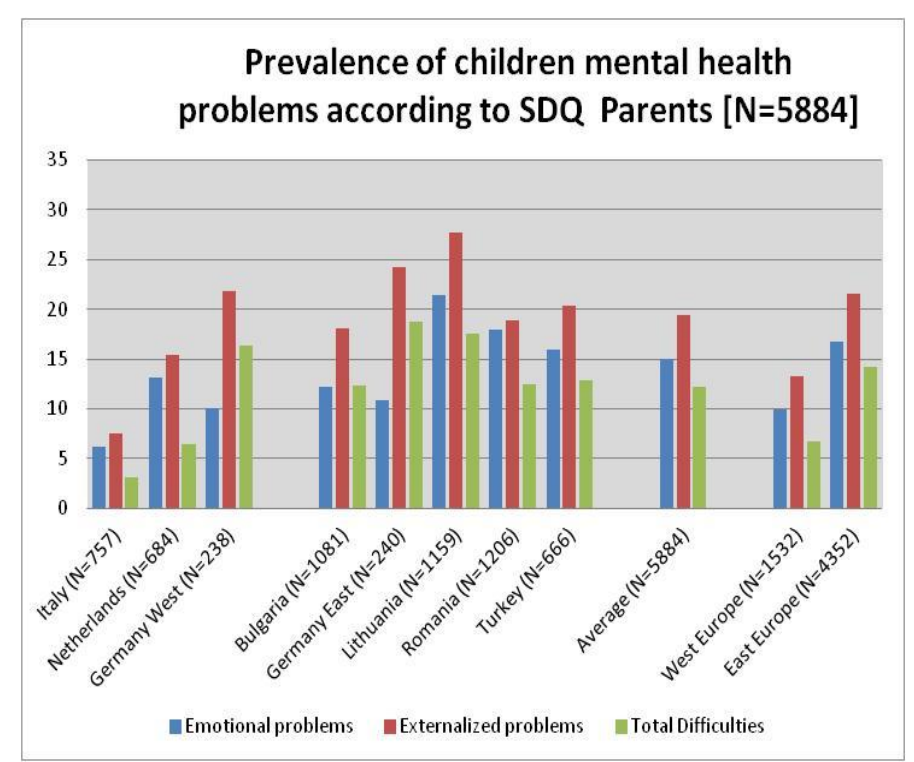

Fig. (3). Prevalence of Children probable cases according SDQ Parents $(n=5884)$.

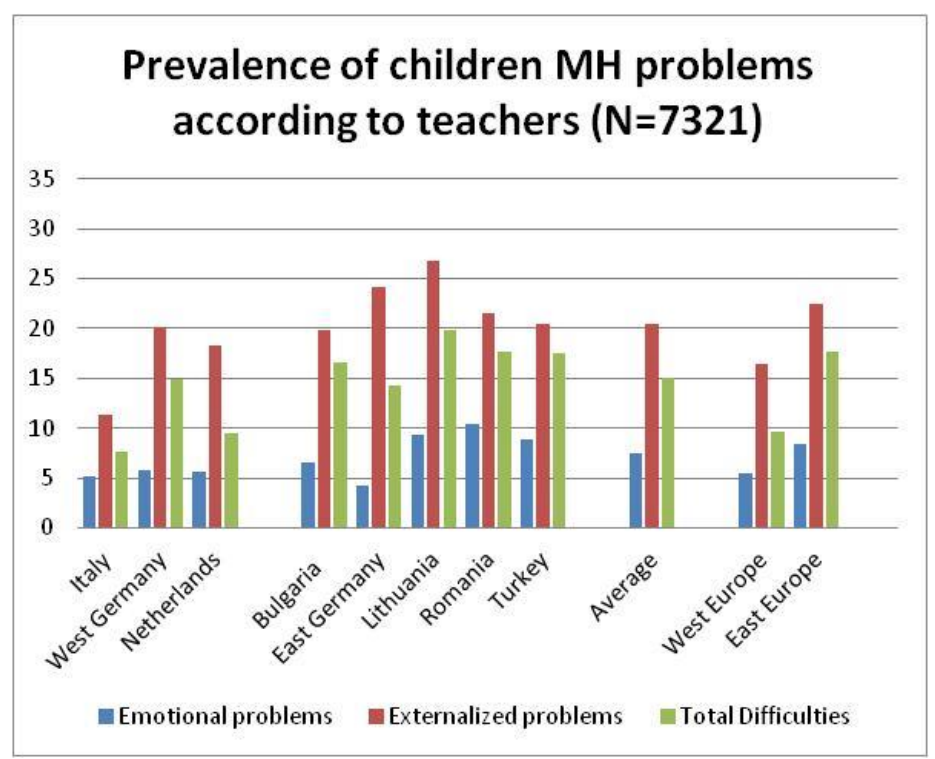

Fig. (4). Prevalence of Children probable cases according to SDQ Teachers $(n=7320)$.

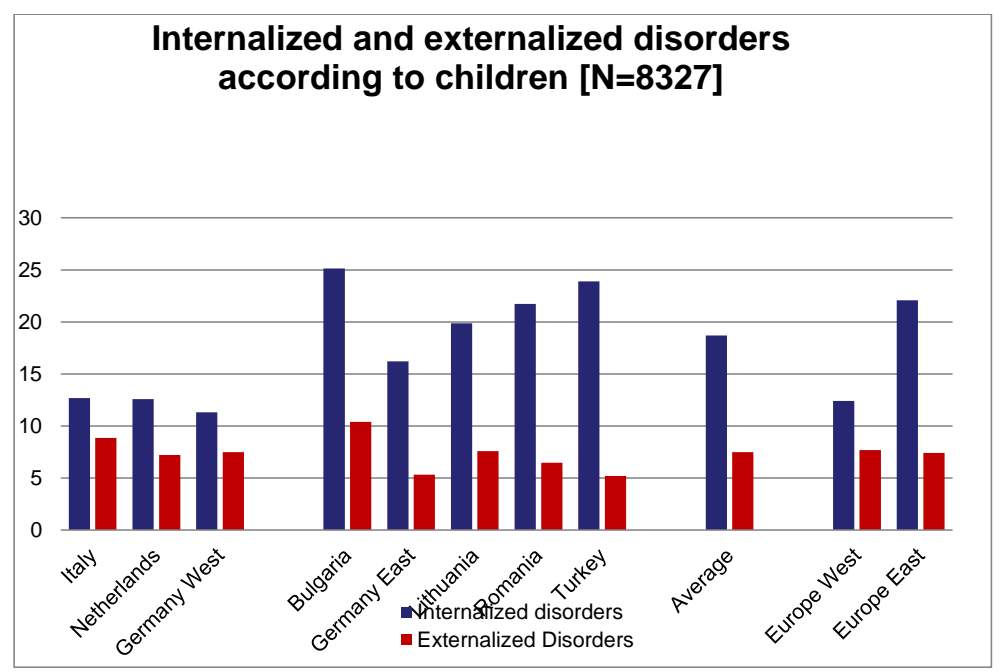

Fig. (5). Prevalence of Children probable cases according DI (children self reported) $n=8327$. 
Table 3. Access to care for those in need for care for MH problems (SDQ parents/teachers combined with children: two informants among them one impact).

\begin{tabular}{|c|c|c|c|c|c|}
\hline & & General Practitioner & $\begin{array}{l}\text { Pediatrician/ } \\
\text { child specialist }\end{array}$ & $\begin{array}{l}\text { No mental health } \\
\text { consultation }\end{array}$ & $\begin{array}{c}\text { No health consultation } \\
\text { at all }\end{array}$ \\
\hline & $\mathbf{N}$ & $\%$ & $\%$ & $\%$ & $\%$ \\
\hline Netherlands & 47 & $63.8 *$ & 29.8 & $57.4 * * *$ & $12.8 * *$ \\
\hline West Germany & 20 & $85^{* *}$ & 60 & 85.0 & 10.0 \\
\hline Bulgaria & 89 & 70.7 & 43.8 & $91.0 *$ & 4.5 \\
\hline East Germany & 21 & 33.3 & 66.7 & 85.7 & 9.5 \\
\hline Lithuania & 160 & 75 & 25.6 & $75.6^{* * *}$ & 7.5 \\
\hline Romania & 101 & 85.1 & 38.6 & $71.3^{* * *}$ & 7.9 \\
\hline TOTAL & 545 & $63.1 *$ & 40 & $76.0 * * *$ & $8.4 *$ \\
\hline
\end{tabular}

Note: "No mental health consultation" meant that children did not see any child psychiatrist, psychologist, psychoanalyst nor psychotherapist for their mental health problems. Note: Linkage test (Fisher's exact test) between the use of health professional (yes/no) and mental care needs (expressed as "Problem with psychiatric needs" vs "Other case or no problem"): * $\mathrm{p}<0.05, * * \mathrm{p}<0.01, * * * \mathrm{p}<0.001$.

rate for Romania $(90.4 \%)$ and the lowest for Italy $(12.5 \%)$. Paediatrician was also the second professional the most consulted with $42.5 \%$, and Germany had the highest rate with $70 \%$ and the Netherlands the lowest with $20 \%$. Among children with non-psychiatric care but requiring any mental health care from primary care system, $16.2 \%$ were cared by psychologist, psychoanalyst and psychotherapist and $11.4 \%$ by a psychiatrist or child psychiatrist. In Germany, no children went to see a psychiatrist, but $25 \%$ were in contact with psychologist and else. In Bulgaria, the psychiatrist was the less contacted with $2.4 \%$ and $7.3 \%$ for the psychologist and else. The highest percentage of children seen by a psychiatrist for these problems was found in Italy $(25 \%)$ and for psychologist and else the highest was found in Romania (34.2\%).

Pooling these categories together, children with problems requiring some sort of mental health care were about $9.9 \%$ : Lithuania $14,4 \%$, Germany $10.3 \%$ and Romania, Turkey and Bulgaria about $9 \%$, and Italy had the lowest rate with 5.8\%. $63.1 \%$ of these children were cared by general practitioner. $40 \%$ were cared by paediatrician or the child specialist. $16.9 \%$ of children with problems requiring any mental health care consulted a psychologist, psychoanalyst or psychotherapist was the third the most consulted and the psychiatrist or child psychiatrist went at the fourth place (with 13\%). Moreover $76 \%$ did not see any mental health professional. In Eastern countries, $78.7 \%$ of these children did not see any mental health consultation in Turkey the percentage was nearly $82.5 \%$ and in Bulgaria 91\%; the situation is a bit better in Western Europe but concern $63.1 \%$ of the children Table 3 .

\subsection{Other Results}

$40 \%$ of the mothers were actually smoking; however important countries differences were found: Bulgaria, Romania and Netherlands were above average whereas Germany, Lithuania and Turkey were below. In addition, attitudes toward smoking in front of children very much differed across countries. Mother's smoking in the vicinity of children was much lower in Germany, Netherlands and Lithuania than in the other countries. Moreover fathers/companions smoked more often in the vicinity of the children than mother did with a substantial difference in the western regions, with $32 \%$ in Bulgaria, $26.5 \%$ in Romania, $24 \%$ in Turkey and $22.1 \%$ in Lithuania versus $5.1 \%$ in Germany and $10.5 \%$ in the Netherlands.

Mothers did not report excess of alcohol consumption and only a few talked about hazardous drinking and particularly in Lithuania where the percentage was above the average $(6.4 \%$ versus $2.2 \%)$. As an average only $10 \%$ of the fathers were respondents but Lithuanian fathers' rate which was above $20 \%$ opposite to the Lithuanian mothers' rate. As expected, percentages of hazardous drinkers were much higher for fathers/companions than for mothers except in Turkey where both parents reported very low rates.

Mothers' attitudes towards their children across countries was not particularly more lax, overreactive or aggressive. For laxness, overreactivity and verbosity, less than $20 \%$ of the mothers had strong behaviour. However, one-fifth to one-fourth of the Lithuanian, German, Dutch and Romanian mothers esteemed that they had strong or weak caring behaviour, opposite to less than $15 \%$ for the Italian and Turkish mothers. Mothers esteemed that they normally promoted autonomy to their child.

\subsection{Published Results Concerning Policies and Specific Topics}

Beside the few results presented here the data bank comprises huge amount of data from countries where economic 
indicators and policies largely differ. This allows to compare some behaviours controlling for some expected predictors, according to these policies or country ecological indicators.

To mention the few that have be published thanks to this data bank it was possible to study

- the different tobacco banning policies and parental attitudes toward smoking in the vicinity of their children with a positive effect (Kovess 2013) [62].

- the policies banning physical punishment and the parental declaration of spanking their children in case of misbehaviour and to find a negative correlation after controlling for most of the social expected predictors (Durivage 2014) [63].

- the positive correlation of the rate of car accidents and the children fear of their parents being victims of a car accident (Sowa 2014) [64].

- nutrition policies and children overweight which show large variation across the countries (Olaya 2014) [65].

Due to the large and diverse samples papers have been written on relationship of each parent tobacco smoking during pregnancy and children ADHD which allows to compare father and mother effect and rule out some hypotheses (Kovess 2014) [66], domestic accidents and parental attitudes and mental health correlated (Keyes 2014) [67], child suicidal thoughts and mental health disorders (Kovess 2014) and the list will continue [68].

\section{CONCLUSION}

This study has proven that measuring young children mental health was feasible and has showed the adaptability of the selected instruments. This suggests its wider applicability to epidemiologic studies in the diverse EU countries. Substantial information was collected regarding family characteristics, parental attitudes, life-style, and their relationship with mental health problems as well mental health needs completed and not completed in a comparable way that could be linked with health systems in the diverse countries.

This survey also increased people awareness of children mental health problems and their consequences on scholastic competences and problems with access to care and underlined the important role of general practitioners and paediatricians.

The first outcome is the development of a toolkit of three brief and easy to administer instruments for surveying primary school mental health, validated against a diagnosis instrument associated completed by clinician's agreement, which is essential for the credibility of the survey results, internationally as well as nationally.

The second outcome is the results of such surveys using those selected instruments in a comparable manner in the seven participating countries, which underlines

- the high prevalence of mental health problems in EU young children population

- the fact that former Eastern European countries have higher rates than Western but after controlling for social determinants the differences are not longer present although inter countries differences persist
- that parental attitudes also differ between global regions and countries and after controlling for social factors remain different across countries

- that access to care for mental health problems for children is low every where in Europe but lower in the East where re-education is still preferred to psychological care compared to the west

Since young children mental health disorders has been linked to further social job positions and securities (Stanfeld S 2008) [69] this study underlines the need to take care of these children at an age a lot of thinks could be done globally on parents trough positive parental attitudes promotion and at the school and individual level on the attention and provision of adequate care.

In addition the project is providing the first ever data on mental health disorders in some countries where this has never been done (Eastern countries and Turkey) plus it provides data from the children perspective and parental attitudes in all participating countries. It is providing mental health data on specific child populations never studied such as the Rom children living in Romania and Bulgaria compared to that one of the no rom children same age (Lee 2014) [70] or children from non native families in Lithuania.

Finally the project brings attention to an age group which is not well studied: the 6 to 11 age range, where many actions could be done before adolescence, a much more difficult period to set up preventive actions

It brought up many data on parental attitudes and their relationship with children mental health and could support parenting interventions

It will also bring attention to the low access to mental health care resources for those kids and sensitise the school systems

It improves knowledge base on mental health by collecting epidemiological data in a specific age group for which data are scares and interventions very promising.

\section{CONFLICT OF INTEREST}

The authors confirm that this article content has no conflict of interest.

\section{ACKNOWLEDGEMENTS}

Declared none.

\section{REFERENCES}

[1] Roberts RE, Attkisson CC, Rosenblatt A. Prevalence of psychopathology among children and adolescents. Am J Psychiat 1998; 155: 715-25.

[2] IOM (Institute Of Medicine). Preventing mental, emotional, and behavioral disorders among young people: progress and possibilities. Washington, DC: Institute of Medicine 2009.

[3] Breton JJ, Bergeron L, Valla JP, Berthiaume C, Gaudet N. Quebec Child Mental Health Survey: Prevalence of DSM-III-R Mental Health Disorders. J Child Psychol Psychiatry 1999; 40: 375-84.

[4] Fergusson DM, Horwood LJ, Lynskey MT. Maternal smoking before and after pregnancy-effects on behavioral outcomes in middle childhood. Pediatrics 1993; 92: 815-22.

[5] Goodman SH, Hoven CW, Narrow WE, et al. Measurement of risk factors for mental disorders and competence in a psychiatric epidemiologic community survey; the National Institute of Mental 
Health Methods for the Epidemiology of Child and Adolescent Mental Disorders (MECA) study. Soc Psychiatry Psychiatr Epidemiol 1998; 33: 162-73.

[6] Meltzer H, Gatward R, Goodman R, Ford T. Mental health of children and adolescents in Great Britain. Int Rev Psychiatr 2003; 15(1): 185-7.

[7] Simonoff E, Pickles A, Meyer JM, et al. The virginia twin study of adolescent behavioural development. Arch Gen Psychiatry 1997; 54: 801-8.

[8] Rutter M, Caspi A, Moffitt T. Using sex differences in psychopathology to study causal mechanisms: Unifying issues and research strategies. J Child Psychol Psychiatry 2003; 44: 1092-115.

[9] Loeber R, Burke JD, Lahey BB, Winters A, Zera M. Oppositional defiant and conduct disorder: a review of the past 10 years, part I. J Am Acad Child Adolesc Psychiatry 2000; 39: 1468-84.

[10] Messer J, Goodman R, Rowe R, Meltzer H, Maughan B. Preadolescent conduct problems in girls and boys. J Am Acad Child Adolesc Psychiatry 2006; 45(2): 184-91.

[11] Angold A, Erkanli A, Farmer EM, et al. Psychiatric disorder, impairment, and service use in rural African American and white youth. Arch Gen Psychiatry 2002; 59(10): 893-901.

[12] Costello EJ, Egger HE, Angold A. 10-year research update review: The epidemiology of child and adolescent psychiatric disorders: I. Methods and public health burden. J Am Acad Child Adolesc Psychiatry $2005 ; 44: 972-86$.

[13] Ford T, Goodman R, Meltzer H. The relative importance of child, family, school and neighbourhood correlates of childhood psychiatric disorder. Soc Psychiatry Psychiatr Epidemiol 2004; 39: 487-96.

[14] Costello E, Angold A, Burns B, et al. The Great Smoky Mountain Study of Youth; goals, designs, methods, and the prevalence of DSM-III-R Disorders. Arch Gen Psychiatry 1996; 5: 1129-36.

[15] Fombonne E. The Chartres study 1. Prevalence of psychiatric disorders among French school-aged children. Br J Psychiatry 1994; 164: 69-79.

[16] Rutter M, Tizard J, Yule W, Graham P, Whitmore K. Isle of Wight Studies, 1964-1974. Psychol Med 1976; 6: 313-32.

[17] Ashford J, van Lier PAC, Timmermans M, Cuijpers P, Hans MK. Prenatal smoking and internalizing and externalizing problems in children studied from childhood to late adolescence. J Am Acad Child Adolesc Psychiatry 2008; 47(7): 779-87.

[18] Batstra L, Hadders-Algra M, Neeleman J. Effect of antenatal exposure to maternal smoking on behavioural problems and academic achievement in childhood: prospective evidence from a Dutch birth cohort. Early Hum Dev 2003; 75: 21-33.

[19] Fergusson DM, Horwood J, Lynskey MT. Prevalence and comorbidity of DSM-III-R diagnoses in a birth cohort of 15 year olds. J Am Acad Child Adolesc Psychiatry 1993; 32: 1127-34.

[20] Wakschlag LS, Pickett KE, Cook E Jr, Benowvitz NL, Leventhal BL. Maternal smoking during pregnancy and severe antisocial behavior in offspring: a review. Am J Public Health 2002; 92: 96674

[21] Wakschlag LS, Pickett KE, Kasza KE, Loeber R. Is prenatal smoking associated with a developmental pattern of conduct problems in young boys? J Am Acad Child Adolesc Psychiatiy 2006; 45: 461-7.

[22] Wasserman GA, Liu XH, Pine DS, Graziano JH. Contribution of maternal smoking during pregnancy and lead exposure to early child behavior problems. Nenrotoxicol Teratol 2001; 23: 13-21.

[23] (i) Weissman MM, Warner V, Wickramaratne PJ, Kandel DB. Maternal smoking during pregnancy and psychopathology in offspring followed to adulthood. J Am Acad Child Adolesc Psychiatry 1999; 38: 892-99. (ii). Achenbach TM. The Achenbach System of Empirically Based Assessemnt (ASEBA): Development, Findings, Theory, and Applications. Burlington, VT: University of Vermont Research Center for Children, Youth and Families 2009.

[24] Williams GM, O'Callaghan M, Najman JM, et al. Maternal cigarette smoking and child psychiatric morbidity. A longitudinal study. Pediatrics 1998; 102: 111.

[25] Chen Y, Weitzman ER. Depressive symptoms, DSM-IV alcohol abuse and their comorbidity among children of problem drinkers in a national survey: Effects of parent and child gender and parent recovery status. J Stud Alcohol 2005; 66: 66-73.

[26] DeLucia C, Belz A, Chassin L. Do adolescent symptomatology and family environment vary over time with fluctuations in paternal alcohol impairment? Dev Psychol 2001; 37: 207-16.
[27] Edwards EP, Leonard KE, Eiden RD. Temperament and behavioral problems among infants in alcoholic families. Inf Mental Health J 2001; 22: 374-92.

[28] Keller PS, Gilbert LA, Koss KJ, Cummings EM, Davies PT. Parental problem drinking, marital aggression, and child emotional insecurity: a longitudinal investigation Stud Alcohol Drugs 2011; 72(5): 711-22.

[29] Johnson J, Cohen P, Kasen S, Smailes E, Brook J. Associatios of maladaptive behaviour with psychiatric disorder among parents and their offspring. Arch Gen Psychiatr 2001; 58: 453-60.

[30] Oyserman D, Bybee D, Mowbray C. Influences of maternal mental illness on psychological outcomes for adolescent chilren. J Adolescence 2002; 25: 587-602

[31] Angold A, Messer SC, Stangl D, Burns EJ. Perceived parental burden and service use for child and adolescent disorders. Am J Public Health 1998; 88: 75-80.

[32] Horwitz SM, Leaf PJ, Leventhal JM. Identification of psychosocial problems in pediatric primary care. Arch Pediatr Adolesc Med 1998; 152: 367-71.

[33] Horwitz SM, Leaf PJ, Leventhal JM, Forsyth B, Speechley KN Identification and management of psychosocial and developmental problems in community-based, primary care pediatric practices. Pediatrics 1992; 89: 480-5.

[34] Horwitz SM, Gary LC, Briggs-Gowan MJ, Carter AS. Do needs drive services use in young children? Pediatrics 2003; $112(6$ Pt 1): 1373-8.

[35] WHO, The World Health Report 2005, Make every mother and child count, WHO, Geneva 2005.

[36] Zwaanswijk M, Van der Ende J, Verhaak PF, Bensing JM, Verhulst FC. Factors Associated with Adolescent Mental Health Service Need and Utilization. J Am Acad Child Adolesc Psychiatry 2003; 42(6): 692-700.

[37] Valla JP, Bergeron L, Smolla N. The Dominic-R: A pictorial interview for 6 to 11 years old children. J Am Acad Child Adolesc Psychiatry 2000; 39 (1): 85-93.

[38] Angold A, Prendergast M, Cox A, Harrington R, Simonoff E, Rutter M. The Child and Adolescent Psychiatric Assessment (CAPA). Psychol Med 1995; 25: 739-53.

[39] Angold A, Costello EJ. A test-retest reliability study of childreported psychiatric symptoms and diagnoses using the Child and Adolescent Psychiatric Assessment (CAPA-C). Psychol Med 1995; 25: 755-62.

[40] Goodman R, Ford T, Simmons H, Gatward R, Meltzer H. Using the Strengths and Difficulties Questionnaire (SDQ) to screen for child psychiatric disorders in a community sample. Br J Psychiatry 2000; 177: 534-9.

[41] Goodman R. The strengths and difficulties questionnaire: a research note. J Child Psychol Psychiatry 1997; 38: 581-6.

[42] Shaffer D, Fisher P, Dulcan MK, et al. The NIMH diagnostic interview schedule for children version 2.3 (disc-2.3): description, acceptability, prevalence rates, and performance in the meca study. methods for the epidemiology of child and adolescent mental disorders study. J Am Acad Child Adolesc Psychiatry 1996; 35(7): 865-77.

[43] Achenbach TM, Edelbrock CS. Behavioral problems and competencies reported by parents of normal and disturbed children aged four through sixteen. Monogr Soc Res Child Dev 1981; 46(1): 182.

[44] Achenbach TM, Rescorla LA. Manual for the ASEBA School-Age Forms \& Profiles. Burlington, VT: University of Vermont, Research Center for Children, Youth, \& Families 2001.

[45] Shojaei T, Wazana A, Pitrou I, et al. Psychometric properties of the Dominic Interactive in a large French sample. Can J Psychiatry 2009; 54(11): 767-76.

[46] Goodman R. The extended version of the Strengths and Difficulties Questionnaire as a guide to child psychiatric caseness and consequent burden. J Child Psychol Psychiatry 1999; 40(5): 791-9.

[47] Goodman R, Ford T, Simmons H, Gatward R, Meltzer H. Using the Strengths and Difficulties Questionnaire (SDQ) to screen for child psychiatric disorders in a community sample. Int Rev Psychiatry 2003; 15(1-2): 166-72

[48] Woerner W, Becker A, Rothenberger A. Normative data and scale properties of the German parent SDQ. Eur Child Adolesc Psychiatry 2004; II3 (Suppl 2): 3-10. 
[49] van Widenfelt BM, Goedhart AW, Treffers PDA, Goodman R. Dutch version of the strengths and difficulties questionnaire (SDQ). Eur Child Adolesc Psychiatry 2003; 12: 281-9.

[50] Smedje H, Broman J-E, Hetta J, von Knorring A-L. Psychometric properties of a Swedish version of the "strengths and difficulties questionnaire. Eur Child Adolesc Psychiatry 1999; 8: 63-70.

[51] Obel C, Heiervang E, Rodriguez A, et al. The strengths and difficulties questionnaire in the Nordic countries. Eur Child Adolesc Psychiatry 2004; 13(Suppl 2): II32-II39.

[52] Malmberg M, Rydell AM, Smedje H. Validity of the Swedish version of the strengths and difficulties questionnaire (SDQ-Swe). Nord J Psychiatry 2003; 57: 357-63.

[53] Koskelainen M, Sourander A, Kaljonen A. The strengths and difficulties questionnaire among Finnish school-aged children and adolescents. Eur Child Adolesc Psychiatry 2000; 9: 277-84.

[54] Marzocchi GM, Capron C, Di Pietro M, et al. The use of the strengths and difficulties questionnaire (SDQ) in Southern European countries. Eur Child Adolesc Psychiatry 2004; 13(Suppl 2): II40-II46.

[55] Saunders JB, Aasland OG, Babor TF, de la Fuente JR, Grant M. Development of the Alcohol Use Disorders Identification Test (AUDIT): WHO collaborative project on early detection of persons with harmful alcohol consumption. II. Addiction 1993; 88: 791804.

[56] Arnold EH, O'Leary SG, Wolff LS, Acker MM. The Parenting Scale: A measure of dysfunctional parenting in discipline situations. Psychol Assess 1993; 5: 137-44.

[57] Bergeron L, Valla JP, Breton JJ. Pilot study for the Quebec Child Mental Health Survey: Part II. Correlates of DSMIII- R criteria among six to 14 years olds. Can J Psychiatry 1992; 37: 381-6.

[58] Ware JE, Sherbourne CD. The MOS 36 short-form health survey (SF-36). I. Conceptual framework and item selection. Med Care 1992; 30(6): 473-83.

[59] Ware JE, Gandek B. Overview of the SF-36 Health Survey and the International Quality Of Life Assessment (IQOLA Project). J Clin Epidemiol 1998; 51: 903-12.
[60] Ware JE, Snow KK, Kosinski M, Gandek B. SF-36 Health Survey: Manual and Interpretation Guide. The Health Institute: New England Medical Center, Boston, MA 1993.

[61] Ware JE, Kosinski M, Keller SD. SF-36 Physical and Mental Component Summary Measures: A User's Manual. The Health Institute: New England Medical Center, Boston, MA 1994.

[62] Kovess V, Pilowsky DJ, Boyd A, et al. Parental smoking in the vicinity of children and tobacco control policies in the European region. PLoS One 2013; 8(2): e56783.

[63] Durivage N, Leray E, Fermanian C, Kovess V. Parental Use of Corporal Punishment in Europe: Intersection between Public Health and Policy. PLoS One 2014; In press.

[64] Sowa D. Car accidents rate and fear of parental accidents in children. [Personal Communication]

[65] Olaya B, Moneta V, Pez O, et al. Association between childhood overweight with mental health problems: Results from the School Children Mental Health in Europe Project European public health conference october 2012 Malta

[66] Kovess v, Keyes K. Maternal smoking and offspring inattention and hyperactivity: results from a cross-national European survey. Eur Child Adolesc Psychiatry 2014 Nov. 21 [Epub Ahead of Print]

[67] Keyes K, Susser E, Pilowsky DJ, et al. The health consequences of child mental health problems and parenting styles: Unintentional injuries among European schoolchildren. Prev Med 2014; 67: 1828.

[68] Kovess V. Suicidal Ideation and mental health disorders in young school children across Europe J Affect Disorder. In Press

[69] Stansfeld SA, Clark C, Caldwell T, Rodgers B, Power C. Psychosocial work characteristics and anxiety and depressive disorders in midlife: the effects of prior psychological distress. Occup Environ Med 2008; 65(9): 634-42.

[70] Lee E, Keyes K, Bitfoi A, et al. Mental Health Disparities between Roma and Non-Roma Children in Romania and Bulgaria. BMC Psychiatry 2014; 14: 297.

Received: September 15, 2014

Revised: October 03, 2014

Accepted: October 05, 2014

(C) Kovess et al.; Licensee Bentham Open.

This is an open access article licensed under the terms of the Creative Commons Attribution Non-Commercial License (http://creativecommons.org/licenses/by-nc/3.0/) which permits unrestricted, non-commercial use, distribution and reproduction in any medium, provided the work is properly cited. 